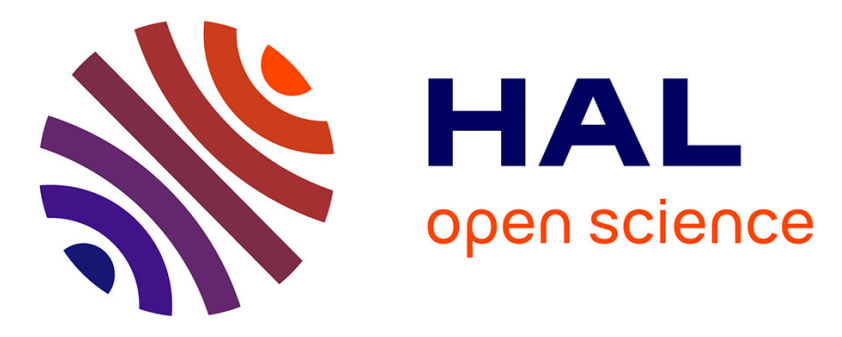

\title{
Biomechanical Modeling to Inform Pulmonary Valve Replacement in Tetralogy of Fallot Patients after Complete Repair
}

Maria Gusseva, Tarique Hussain, Camille Hancock Friesen, Philippe Moireau, Animesh Tandon, Cécile Patte, Martin Genet, Keren Hasbani, Gerald Greil, Dominique Chapelle, et al.

\section{To cite this version:}

Maria Gusseva, Tarique Hussain, Camille Hancock Friesen, Philippe Moireau, Animesh Tandon, et al.. Biomechanical Modeling to Inform Pulmonary Valve Replacement in Tetralogy of Fallot Patients after Complete Repair. Canadian Journal of Cardiology, 2021, 37, pp.1798-1807. 10.1016/j.cjca.2021.06.018 . hal-03313844

\author{
HAL Id: hal-03313844 \\ https://hal.inria.fr/hal-03313844
}

Submitted on 5 Aug 2021

HAL is a multi-disciplinary open access archive for the deposit and dissemination of scientific research documents, whether they are published or not. The documents may come from teaching and research institutions in France or abroad, or from public or private research centers.
L'archive ouverte pluridisciplinaire HAL, est destinée au dépôt et à la diffusion de documents scientifiques de niveau recherche, publiés ou non, émanant des établissements d'enseignement et de recherche français ou étrangers, des laboratoires publics ou privés. 


\section{Title}

Biomechanical Modeling to Inform Pulmonary Valve Replacement in Tetralogy of Fallot Patients after Complete Repair

\section{Short title}

Biomechanical Modeling in Valve Replacement

\section{Authors}

Maria Gusseva, MS 1,2

Tarique Hussain, $\mathrm{MD}, \mathrm{PhD}^{3}$

Camille Hancock Friesen, $\mathrm{MD}^{4}$

Philippe Moireau, $\mathrm{PhD}^{1,2}$

Animesh Tandon, $\mathrm{MD}^{3}$

Cécile Patte, $\mathrm{PhD}^{1,2}$

Martin Genet, $\mathrm{PhD}^{1,2}$

Keren Hasbani, MD 5

Gerald Greil, MD, $\mathrm{PhD}^{3}$

Dominique Chapelle, $\mathrm{PhD}^{1,2}$

Radomír Chabiniok, MD, $\mathrm{PhD}^{1,2,3,6,7}$

\section{Affiliations}

${ }^{1}$ Inria, Palaiseau, France

2LMS, Ecole Polytechnique, CNRS, Institut Polytechnique de Paris, Palaiseau, France ${ }^{3}$ Division of Pediatric Cardiology, Department of Pediatrics, UT Southwestern Medical Center, Dallas, TX

${ }^{4}$ Division of Pediatric Cardiothoracic Surgery, Department of Pediatrics, UT Southwestern Medical Center, Dallas, TX

${ }^{5}$ Division of Pediatric Cardiology, Department of Pediatrics, Dell Medical School, UT Austin, TX

${ }^{6}$ School of Biomedical Engineering \& Imaging Sciences, St Thomas' Hospital, King's College London, UK

${ }^{7}$ Department of Mathematics, Faculty of Nuclear Sciences and Physical Engineering, Czech Technical University in Prague, Czech Republic

\section{Corresponding Author}

Radomír Chabiniok, MD, PhD

Address: Department of Pediatrics, UT Southwestern Medical Center, 5323 Harry Hines Blvd, Dallas, TX 75390, USA

Tel: +12144567311

E-mail: radomir.chabiniok@UTSouthwestern.edu 


\section{Brief Summary}

Clinical indicators derived directly from imaging or cardiac catheterization are known to have limited ability to predict post-interventional reverse-remodeling in patients with chronic valvular disease. Coupling clinical data with biomechanical modeling in 20 tetralogy of Fallot patients after complete repair allowed derivation of composite indicators of heart function. Comparative influences of residual right ventricular outflow tract obstruction and pulmonary regurgitation on ventricular health were assessed. Personalized biomechanical models represent a potential to tailor clinical management. 


\section{Abstract}

Background: A biomechanical model of the heart can be used to incorporate multiple data sources (ECG, imaging, invasive hemodynamics). The purpose of this study was to use this approach in a cohort of tetralogy of Fallot patients after complete repair (rTOF) to assess comparative influences of residual right ventricular outflow tract obstruction (RVOTO) and pulmonary regurgitation on ventricular health.

Methods: 20 rTOF patients who underwent percutaneous pulmonary valve replacement (PVR) and cardiovascular magnetic resonance (CMR) were included in this retrospective study. Biomechanical models specific to individual patient and physiology (pre- and post-PVR) were created and utilized to estimate the RV myocardial contractility. The ability of models to capture post-PVR changes of RV enddiastolic volume (EDV) and effective flow in pulmonary artery (Qeff) was also compared to expected values.

Results: RV contractility pre-PVR $(65 \pm 17 \mathrm{kPa}$, mean $\pm \mathrm{SD})$ was increased in $\mathrm{rTOF}$ patients in comparison to normal RV $(39-45 \mathrm{kPa})(\mathrm{p}<0.05)$. The contractility decreased significantly in all patients post-PVR $(p<0.05)$. Patients with predominantly RVOTO demonstrated greater reduction in contractility (median decrease 35\%) post-PVR than those with predominant pulmonary regurgitation (median decrease $12 \%$ ). The model simulated post-PVR decreased EDV for majority and suggested an increase of Qeff both in line with published data.

Conclusions: This study uses a biomechanical model to synthesize multiple clinical inputs and give an insight into RV health. Individualized modeling allows us to predict the RV response to PVR. Initial data suggest that residual RVOTO imposes greater ventricular work than isolated pulmonary regurgitation. 
Keywords: Translational research; Cardiovascular modeling; Myocardial contractility; Tetralogy of Fallot; Personalized medicine; Cardiovascular magnetic resonance imaging 


\section{Abbreviations and acronyms}

$\begin{array}{ll}\text { BSA } & \text { body surface area } \\ \text { CI } & \text { confidence interval } \\ \text { CMR } & \text { cardiovascular magnetic resonance } \\ \text { EDV } & \text { end-diastolic volume } \\ \text { EDP } & \text { end-diastolic pressure } \\ \text { ESP } & \text { end-systolic pressure } \\ \text { ESV } & \text { end-systolic volume } \\ \text { EF } & \text { ejection fraction } \\ \text { HR } & \text { heart rate } \\ \text { EDVi } & \text { end-diastolic volume indexed to body surface area } \\ \text { ESVi } & \text { end-systolic volume indexed to body surface area } \\ \text { LV } & \text { left ventricle } \\ \text { PA } & \text { pulmonary artery } \\ \text { PR } & \text { pulmonary regurgitation } \\ \text { P-V loop } & \text { ventricular pressure-volume loop } \\ \text { PVR } & \text { pulmonary valve replacement } \\ \text { QRSd } & \text { duration of QRS complex } \\ \text { TOF } & \text { tetralogy of Fallot } \\ \text { RF } & \text { regurgitant fraction } \\ \text { rTOF } & \text { repaired tetralogy of Fallot } \\ \text { RV } & \text { right ventricle } \\ \text { RVOT } & \text { right ventricular outflow tract } \\ \text { RVOTO } & \text { right ventricular outflow tract obstruction } \\ \text { SD } & \text { standard deviation } \\ \text { SV } & \text { stroke volume } \\ \text { TP } & \text { tricuspid regurgitation } \\ \text { TV } & \text { tricuspid valve } \\ & \end{array}$




\section{Introduction}

Stenosis of the pulmonary valve is a relatively common congenital condition isolated, or as a part of the constellation of tetralogy of Fallot (TOF). The initial pressure overload is corrected surgically often using a transannular patch causing varying degrees of pulmonary regurgitation (PR). Over time valve-sparing techniques have been preferred, but at the cost of potentially higher rates of residual right ventricular outflow tract obstruction (RVOTO). Chronic RV volume overload leads to RV dilatation while chronic RVOTO can cause RV hypertrophy. To avoid RV failure and even to allow reverse-remodeling, patients undergo a pulmonary valve replacement (PVR) in adolescence or early adult life. There is a robust debate regarding the optimal timing of $\mathrm{PVR}^{1-7}$. Among the main clinical indicators considered in decision-making are the degree of $\mathrm{RV}$ dilatation, $\mathrm{RV}$ ejection fraction (EF) or pulmonary valve regurgitation fraction $(\mathrm{RF})^{8}$. However, the ability to predict post-PVR reverse-remodeling remains elusive and is only witnessed in $60 \%$ of patients regardless of the threshold for intervention ${ }^{2}$. Upstream, the debate as to the optimal initial repair remains whether transannular patch with mild residual obstruction is preferable to annulus sparing approaches in borderline valves. Current practice is to favor valve preservation but recent long-term outcome data suggests that RV hypertrophy may be a predictor of adverse events ${ }^{9}$.

While the current guidelines focus on the direct measures taken from imaging data, the underlying physiology is not the primary driver of interventions. Incorporating physical and physiological assumptions of cardiovascular function in the framework of biomechanical modeling ${ }^{10,11}$ has the potential to augment the interpretation of clinical data, such as by estimating some clinically relevant functional quantities - e.g. myocardial contractility ${ }^{12-14}$. The contractility in the present work represents the active 
stress generated by the myocardial sarcomere unit during contraction. The contractility in a given patient can be increased chronically (e.g. in chronic ventricular overloading such as due to a valvular defect) and adapts to the actual physiological state by inotropic stimulation ${ }^{14}$. We remark that the level of myocardial contractility - as used in this work - was demonstrated to correlate with the maximum time derivative of ventricular pressure, max $(\mathrm{dp} / \mathrm{dt})^{14}$, which is a widely accepted surrogate measure of global ventricular contractility. Assessing mechanical properties of the hearts of tetralogy of Fallot patients after complete repair (rTOF) provides additional metrics which may give a new insight into the initial procedure choice in cases of borderline pulmonary valve annulus.

\subsection{Objectives}

The goal of this retrospective observational work is to quantify the level of RV myocardial contractility pre-PVR and immediately post-PVR by coupling the available clinical data with a biomechanical model. We hypothesize that the RV contractility is chronically increased in rTOF patients with PR or residual RVOTO and that it will decrease immediately post-PVR. This reduction towards the normal values will also translate into the reduction of stroke work that the heart needs to exert.

\section{Material and methods}

\subsection{Data}

A group of 20 rTOF patients, who underwent percutaneous PVR, were included in this retrospective study. The data collections were performed under the ethical approvals of Institutional Review Boards of UT Southwestern Medical Center Dallas (STU-2020- 
0023) and UT Austin (IRB 2020-06-0128). The IRBs waived the need for a consent to use the anonymized retrospective data.

All patients underwent cardiovascular magnetic resonance (CMR) exam 4-6 months before PVR. CMR was processed semi-automatically by using the CVI42 software (Circle Cardiovascular Imaging Inc., Calgary, Canada) and a finite element method for image registration ${ }^{15,16}$. The results of CMR analyses are RV time-vs-volume plots, and time-vs-flow through the pulmonary artery (PA) together with the flow integrated throughout the cycle containing the forward and regurgitant components (Qtor, Qback, respectively). The effective flow through the pulmonary circulation (i.e. Qtor - Qback) will be denoted by Qeff.

During the percutaneous PVR, the right-heart pressures (containing right atrial, $R V$ and PA pressures) were taken prior to and after deploying the valve. Figure 1 displays an example of processed clinical data of a selected patient.

Supplementary Table S1 provides information about the baseline anatomy, possible palliation, type and age of TOF repair, re-intervention (if any) and the type of prosthesis in each patient.

Data of a healthy subject were obtained from a population study ${ }^{17}$ that contained the values (weighted means) of: RV and PA end-systolic pressures (ESP); RV EDV and ESV; and RV myocardial mass.

\subsection{Biomechanical model}

The biomechanical heart model of reduced order ${ }^{18,19}$ was employed. While the geometry and kinematics of RV are reduced, the constitutive mechanical laws are preserved as in the full 3D heart model ${ }^{20}$ (Figure 2). Specifically, myocardial tissue was modeled by a visco-elastic material with active contractile component representing the 
actin-myosin interaction (consistent with the sliding filament theory by $A$. F. Huxley ${ }^{21,22}$ ). The myocardial internal stresses - passive (given by the tissue stiffness of the visco-elastic material) and active (generating the active shortening of the myocardial fibers leading to heart contraction) - are in the equilibrium with the external loading (the pressure exerted on the endocardial surface) and inertia forces. The model of RV was connected to a Windkessel model of circulatory system ${ }^{23}$, which consisted of proximal resistance and capacitance $R_{\text {prox }}, C_{\text {prox }}$ (representing the main and branch pulmonary arteries, with pressure $P_{a r}$, and distal resistance and capacitance $R_{\text {dist, }} C_{\text {dist }}$ (representing the remaining pulmonary circulation, with

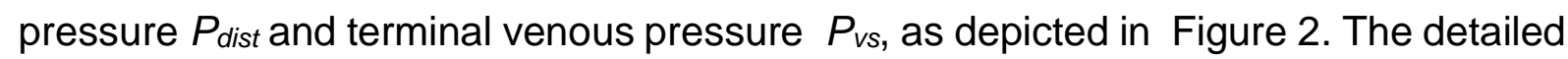
description of the model is provided in the Supplementary Material and rigorous formulations can be found in our previous works ${ }^{18,20,24}$.

\subsection{Model calibration to data of individual patients}

The biomechanical model of RV and pulmonary circulation was adjusted manually to the data of each individual patient by a sequential calibration ${ }^{19}$.

The pulmonary Windkessel model was adjusted while imposing the measured PA flow. Using cine MRI, we prescribed the wall thickness and the ventricular volume in stressfree configuration (when zero intraventricular pressure is assumed) ${ }^{25}$. The RV preload was prescribed according to the measured RV pressure in diastole. Passive myocardial properties (i.e. myocardial stiffness) were calibrated so that the simulated EDV matched the measurement. RVOT was modeled as an outlet valve allowing the forward and regurgitant flow ${ }^{24}$ (with resistances $R_{\text {for }}^{R V O T}$ and $R_{\text {back }}^{R V O T}$, respectively). The backward resistance $R_{\text {back }}^{R V O T}$ was adjusted to match the backward flow waveform. $R_{\text {back }}^{R V O T}$ was set to a very high value if no pulmonary regurgitation (PR) was present (effectively 
zero backward conductance). Similarly, a negligible $R_{\text {for }}^{R V T}$ was used if no pathological RVOT obstruction was present. The tricuspid valve (TV) was modeled as an inlet valve with forward and backward resistances $R_{f o r}^{T V}$ and $R_{\text {back }}^{T V}$, respectively ${ }^{26}$. The myocardial contractility was adjusted according to the measured RV stroke volume (SV) and RV ESP. Physiological assumptions of mechano-chemical coupling of the actin-myosin complex in the sarcomere are translated into the mechanical system generating force - the active contractility - which combines with the passive visco-elastic properties of the tissue.

The post-PVR model was obtained by re-calibrating the pre-PVR model with the aim to match the post-PVR pressure measurements. We preserved the passive myocardial properties; prescribed the preload as in the measurement; $R_{\text {back }}^{R V O T}$ was set to its maximum (to eliminate $\mathrm{PR}$ ) and $R_{\text {for }}^{R V O T}$ adjusted to match the pressure difference between RV and PA. Finally, the myocardial contractility was adjusted so that the simulated RV ESP matched the data.

The mechanical parameters of these patient-specific models give an insight into the cardiovascular physiology of each patient. The simulated RV EDV and pulmonary flow post-PVR were used to validate the model prediction against published data by Lurz et $\mathrm{al}^{27}$.

Further details of the model calibration, including quantitative values of parameters for each patient (Supplementary Table S2), are presented in Supplementary Material.

\subsection{Statistical analysis}

Wilcoxon signed-rank tests were conducted for the changes in model-derived contractility and PA ESP at $p<0.05$. Bland-Altman plots were constructed to evaluate the difference between simulated and measured functional indicators. 


\section{Results}

\subsection{Direct analysis of clinical data}

Table 1 summarizes the demographics and results of direct analysis of clinical data. Pre-PVR CMR revealed that $45 \%$ of patients had mild PR, with RF of $10-30 \% ; 15 \%$ of patients had moderate PR (RF $30-40 \%$ ); and $40 \%$ had severe PR (RF>40\%). Considering the RV size, $25 \%$ of patients had moderate RV dilatation (end-diastolic volume indexed to the body surface area RV EDVi $120-140 \mathrm{ml} / \mathrm{m}^{2}$ ); and $20 \%$ had moderate-to-severe RV dilatation (RV EDVi $140-150 \mathrm{ml} / \mathrm{m}^{2}$ ), while the remaining patients had normal or mildly dilated RV. Finally, $30 \%$ of patients had moderate pulmonary stenosis with the RV to PA pressure gradient of at least $25 \mathrm{mmHg}$. The degree of RVOTO was evaluated based on the ratio of RV to LV ESP, where ratio $\geq 50 \%$ ( $<50 \%)$ was considered as high (low, respectively) degree of RVOTO. The comparison of RV SV and outflow volume Qtor revealed a mild TR in 4 patients.

The patients were divided into 3 groups according to the level of RVOTO and PR: Patients with low degree of RVOTO and at least moderate PR (Group A); high degree of RVOTO and mild PR (Group B); and high degree of RVOTO and at least moderate PR (Group C). Groups A-C contained 9, 8 and 3 patients, respectively.

\subsection{Model-derived ventricular contractility}

We have successfully calibrated the model for all patients pre- and post-PVR. Figure 3 and Supplementary Figures S1-S3 show the simulated cardiac cycles confronted with data in selected patients. Bland-Altman plots in Figure 4 and quantitative summary in Table 2 show the mean bias \pm standard deviation (SD) between the simulations and measurements pre- and post-PVR. 
Calibrating the model by using the data of healthy population revealed the contractility of healthy $\mathrm{RV}$ to be in the range of $38-48 \mathrm{kPa}$. The values of $\mathrm{RV}$ contractility in all patients (assessed by models calibrated to pre- and post-PVR data) are plotted against RV ESP in Figure 5A. Pre- and post-PVR median contractility was 66 and $51 \mathrm{kPa}$, respectively. Figure $5 B$ shows a strong positive correlation $\left(R^{2}=0.95, p<0.001\right)$ between the RV ESP and contractility rescaled by the ratio of myocardial wall thickness over ventricular radius.

Stroke work was calculated as the area encompassed within the simulated ventricular pressure-volume $(\mathrm{P}-\mathrm{V})$ loops and is plotted against RV ESP in Figure 5C. Pre- and post-PVR median stroke work was 327 and $233 \mathrm{~mJ}$, respectively. The stroke work obtained from the healthy subjects was $103-150 \mathrm{~mJ}$.

The values of mean contractility and stroke work for each group, relative to the maximum values of the normal population, are presented in Table 3.

\subsection{Post-PVR changes in RV EDV and effective PA flow}

The patient-specific post-PVR models created in Section 4.2 were used to assess the changes of RV volumes and PA flow post-PVR based on captured post-PVR invasive pressures. Figure 6 shows the model-derived changes of RV EDVi and PA effective flow Qeff. An average EDP decrease in our cohort was lower compared to the study of Lurz et al. ${ }^{27}, 14.2$ vs. $26.5 \%$. Consequently, an average EDV decrease was also lower, $3 \%$ decrease suggested by the model vs. $12 \%$ reported by Lurz et al. The model suggested an increase of PA Qeff post-PVR, which fell between the values of Qfor and Qeff pre-PVR - in line with Lurz et al.

\section{Discussion}


The present study applied patient-specific biomechanical modeling on a group of rTOF patients indicated for PVR. We aimed to assess whether the proposed data-model coupling framework provides any additional clinical indicators of the effects of PVR therapy.

CMR and pressure-derived clinical indicators suggested 3 groups of patients based on the grade of PR and severity of RVOTO. The patient-specific models created separately for pre-and post-PVR physiology revealed that PVR triggered an immediate adaptation of RV contractility for a majority of patients with a decrease of the median contractility by $23 \%$. Table 2 reveals that the patients with a high degree of RVOTO showed a larger contractility decrease (Groups B and C) and the contractility of all patients decreased close to the normal values (Table 2 and Figure 5).

The stroke work represents the mechanical energy generated by the ventricle during a heartbeat. The analysis of P-V loops suggested that even though the patients with a high degree of RVOTO (Groups B and C) experienced a significant decrease of the median stroke work (Table 2), the actual stroke work after post-PVR remained elevated due to a limited decrease of $R V$ pressure post-PVR. The patients with predominantly PR and a low degree of RVOTO (Group A) showed a decrease of the median stroke work by $17 \%$. The resulting stroke work was only around $10 \%$ above normal values (Table 2), thanks to the normal RV pressure post-PVR.

The strong correlation between the ventricular pressure and the rescaled contractility is in line with Laplace's law of myocardial wall stress being directly proportional to the level of pressure developed in the chamber for a given geometry during ventricular systole. Hence, prior to PVR we observed higher levels of contractility in patients with increased RV systolic pressure and in those with dilated RVs (Patients \#12 and \#14 from Group B). The RV contractility decreased post-PVR primarily due to the release 
of RVOTO. The sole effect of regurgitation on the system was visible in the patients from Group A. The median contractility and stroke work in this group appeared to be only up to $4 \%$ and $34 \%$ higher, respectively, than a range of reference healthy RV contractility and stroke work (Table 2). This suggests that, in infants with TOF with borderline pulmonary valve annulus, inserting a transannular patch might be preferential, as the RV is likely to well tolerate the created PR. However, two patients with most dilated RVs (RV EDVi>140 $\mathrm{ml} / \mathrm{m}^{2}$ ) appeared to be the outliers with the prePVR contractility of 77 and $73 \mathrm{kPa}$ (Patients \#12 and 14, respectively). It is likely that prior to PVR, the majority of patients in Group A had been preserving their cardiac output at moderately elevated myocardial stresses. Those with dilated RVs had been progressively becoming less efficient and had elevated metabolic demands. Therefore, our model revealed that the myocardial contractility was substantially increased in the patients with dilated RVs prior to PVR. However, the critical range of RV dilatation is unclear from this study and is the subject of our ongoing work. Furthermore, we showed that the greatest reduction of contractility occurred due to removal of RVOTO, while removing the regurgitation itself did not lead to a significant immediate decrease of contractility in the majority of patients.

Not having post-PVR CMR prevented us from performing a detailed validation of our post-PVR models. However, a partial validation was possible thanks to the study by Lurz et al. ${ }^{27}$, in which CMR was performed immediately after the intervention on pulmonary valve. Our models showed a decrease of RV EDV for patients experiencing a decrease in RV EDP and an increase of PA Qeff post-PVR, which both qualitatively match with the study of Lurz et al. The lower decrease of EDP (as measured in our patients in comparison to Lurz et al.) explains the lower EDV decrease in our group of patients. 


\subsection{Limitations}

A number of limitations should be addressed. First, an assumption of spherical RV might have overestimated the contractility since the spherical shape is mechanically more efficient than a crescent shape. Figure 7 demonstrates the effect of interobserver variability in estimating RV myocardial mass: the difference between pre- vs. post-PVR contractility were preserved in relative sense and this would be expected also if an accurate RV geometry was used. It is expected that the active stress developed in various parts of the $R V$ varies (e.g. inflow part may be very contractile, while the outflow will be hypo- or dyskinetic due to the passive transannular patch). Such a heterogeneity cannot be captured by our simplified modeling approach. However, our pilot study demonstrates that employing such a modeling approach is feasible directly in the clinical setup. The level of complexity of the model allows medical doctors to set up the patient-specific models. This may facilitate launching a large-scale and multisite clinical study counting hundreds of cases, which would be out-of-reach for a number of complex models.

Percutaneous PVR is mostly not used in patients with very dilated RVs and RV outflow tracts. Such patients rather undergo surgical PVR. In this pilot study we took advantage of the accessibility of measured pressures post-PVR. However, we acknowledge that the population in our study was biased and did not allow for general conclusions regarding relative impact of PR and pulmonary stenosis over the whole range of this patient population. In the future study, we aim to use an estimated of RVOT pressure gradient based on the measured flow profile through $\mathrm{RVOT}^{28}$ and the estimated enddiastolic RV pressure according to the right atrial volume and the flow through tricuspid 
valve ${ }^{29}$. Including such modeling components will not limit the participants of the study to those undergoing percutanenous PVR.

The other important concern is the time period of 4-6 months between the acquisition of CMR and catheterization data in this proof-of-concept work. The progressive RV remodeling might have caused an underestimation of the current $\mathrm{RV}$ volumes, which may in turn affect the predicted model-derived properties. Finally, the validation of our post-PVR model was limited due to the absence of post-PVR CMR data. In the future we aim to perform an additional CMR exam within 48 hours post-PVR, which would be plausible for most patients. RV electromechanical dyssynchrony is another major pathophysiological factor, which can lead to further pathological RV remodeling in rTOF patients; electrical data was not assessed in this study. However, cardiac models with a detailed electrical component have the perspective in optimizing the right ventricular cardiac resynchronization therapy $\mathrm{RV}-\mathrm{CRT}{ }^{30}$, and modeling could even contribute to the decision making of a possible combination of PVR and RV-CRT.

\subsection{Future Perspectives}

Decreased contractility and stroke work post-PVR suggest a possible decrease in myocardial metabolic rate and oxygen demand, which could be in principle validated by the Fick principle. In addition to RV contractility at rest, a reduced exercise capacity may play a significant role in the response to PVR and will be studied ${ }^{14,31}$. Automatization of the model setup, would allow the performance of a sensitivity analysis ${ }^{32}$ and is a necessary step to translate the present proof-of-concept work into clinical practice. The present work demonstrates an application of models capturing an immediate state of the cardiovascular system to inform about the current physiological state without explicitly considering the previous progress of ventricular remodeling. 
Models of long-term evolution - growth \& remodeling $(G \& R)$ models ${ }^{33,34}$ - could have the potential to include the information about the initial state of pathology, type of repair as well as the evolution throughout the life of patient (see Supplementary Table S1). In addition, advanced imaging techniques such as the assessment of myocardial fiber directions by $\mathrm{MRI}$ diffusion tensor imaging ${ }^{35,36}$ could be considered in the future. Models capturing the long-term effects could be also useful in better understanding the long-term reverse-remodeling post-PVR (when longitudinal data will be gathered) as well as in predicting the long-term effect of PVR.

Even though our study demonstrated a substantially increased work that the RV must exert in patients with residual RVOT obstruction and therefore favors transannular patch in the case of borderline annulus size we are aware that our proof-of-concept modeling study cannot have immediate implications on patient care. Furthermore, it is known that a mild to moderate stenosis in the early post-operative period may spontaneously regress and the strategy of preservation of annular function may be compatible with long-term relief of RVOT obstruction in many cases. While this is out of scope of the present paper, characterizing the long-term cardiac growth and remodeling is the subject of ongoing research ${ }^{37,38}$.

\section{Conclusion}

Combination of computational models and clinical data is feasible in a cohort of rTOF patients. Such patient-specific models have the potential to assess clinically relevant mechanical and physiological properties and subsequently predict outcomes of PVR for individual patients. Specifically, the study quantifies the level of volume- or pressure-overload of RV with chronic valvular disease and how the level of overloading decreases after intervention on the valve. While not directly predicting who should 
undergo PVR and who should wait, we believe our physiological finding is of a clinical interest as a step towards optimal clinical evaluation and management of patients with valvular heart disease. Furthermore, the need to aim for long-term relief of RVOT obstruction is highlighted, perhaps prejudicing the initial surgical approach.

This proof-of-concept work paves the way for a prospective study to assess the sensitivity and specificity of mechanical indices obtained by including biomechanical modeling. Such predictions based on coupling clinical data and biomechanical models have the potential to become part of clinical assessment to contribute into optimizing and personalizing the clinical management of every patient.

\section{Funding sources}

This work was supported by the Inria-UTSW Associated Team TOFMOD; Wellcome/EPSRC Centre for Medical Engineering [WT 203148/Z/16/Z]; and the Ministry of Health of the Czech Republic [NV19-08-00071] to R. Chabiniok. It was also funded in part from by the W. B. \& Ellen Gordon Stuart Trust, The Communities Foundation of Texas and by the Pogue Family Distinguished Chair (award to Dr F. Gerald Greil in February, 2015). Research reported in this publication was supported by Children's Health ${ }^{S M}$ but the content is solely the responsibility of the authors and does not necessarily represent the official views of Children's Health ${ }^{S M}$.

\section{Disclosures}

Conflict of interests: none declared. 

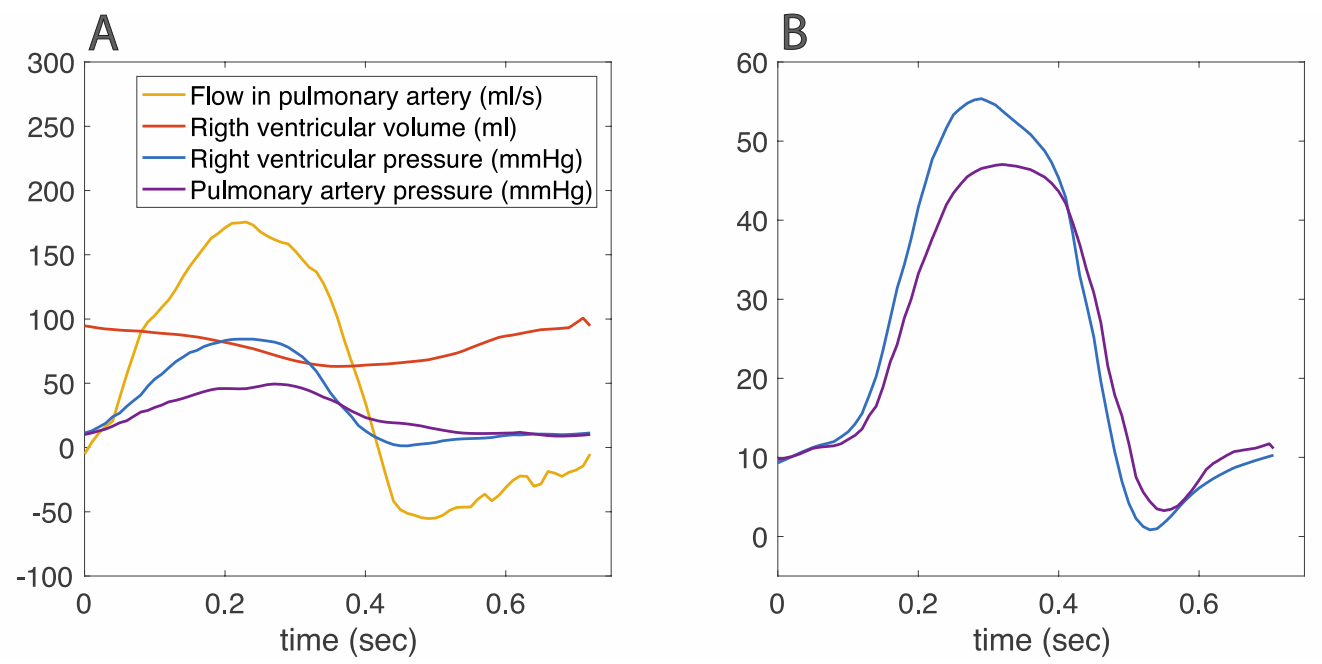

Figure 1: Example of processed clinical data prior to (A) and after (B) pulmonary valve replacement (PVR). 


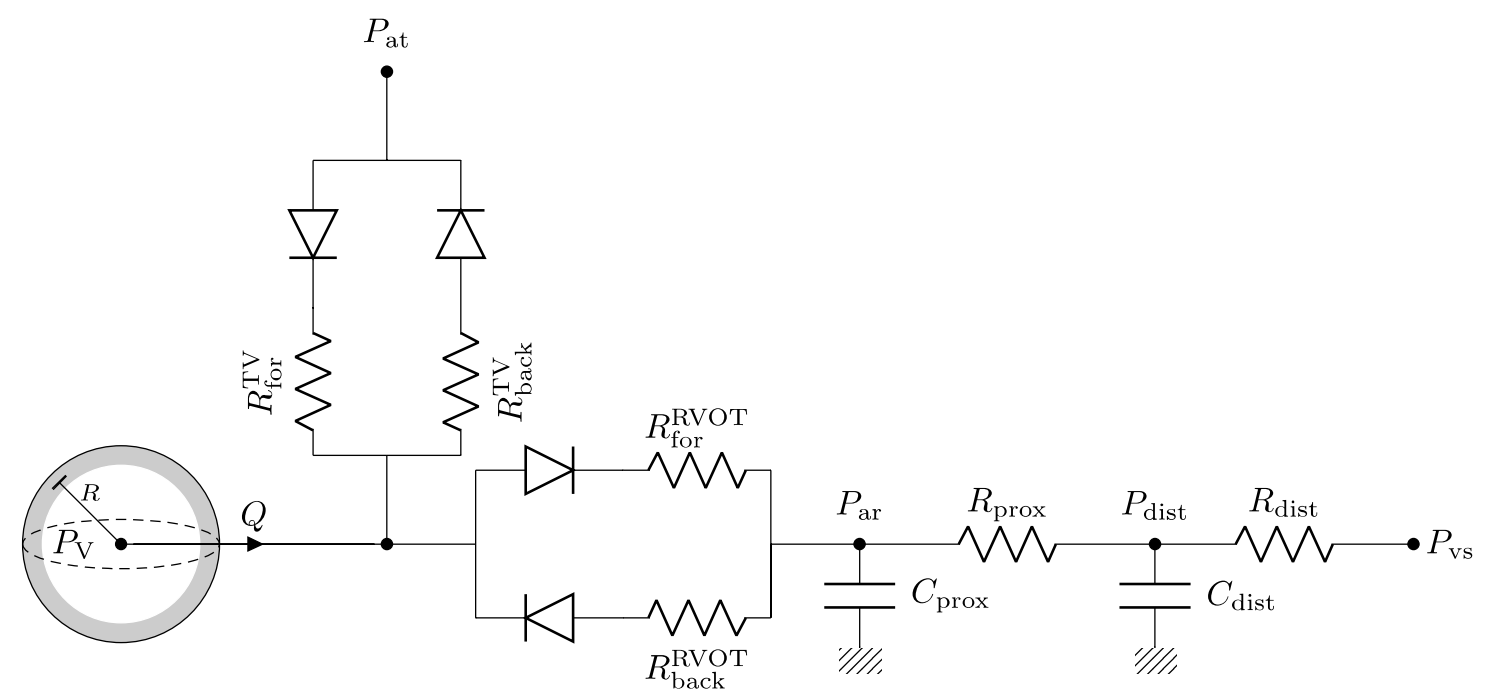

Figure 2: Model of right ventricle coupled with atrioventricular and arterial outflow valves and with circulation system represented by a Windkessel model. $P_{\mathrm{v}}, P_{\mathrm{at}}, P_{\mathrm{ar}}$, $P_{\text {dist }}$ and $P_{v s}$ stand for pressures in ventricle, atrium, large arteries, distal circulation and venous system, respectively; and are forward and backward resistances of the tricuspid valve; and are forward and backward resistances of the ventricular outflow track; $R_{\text {prox }}, R_{\text {dist }}, C_{\text {prox }}, C_{\text {dist }}$ are proximal and distal resistances and capacitances of the circulation. 

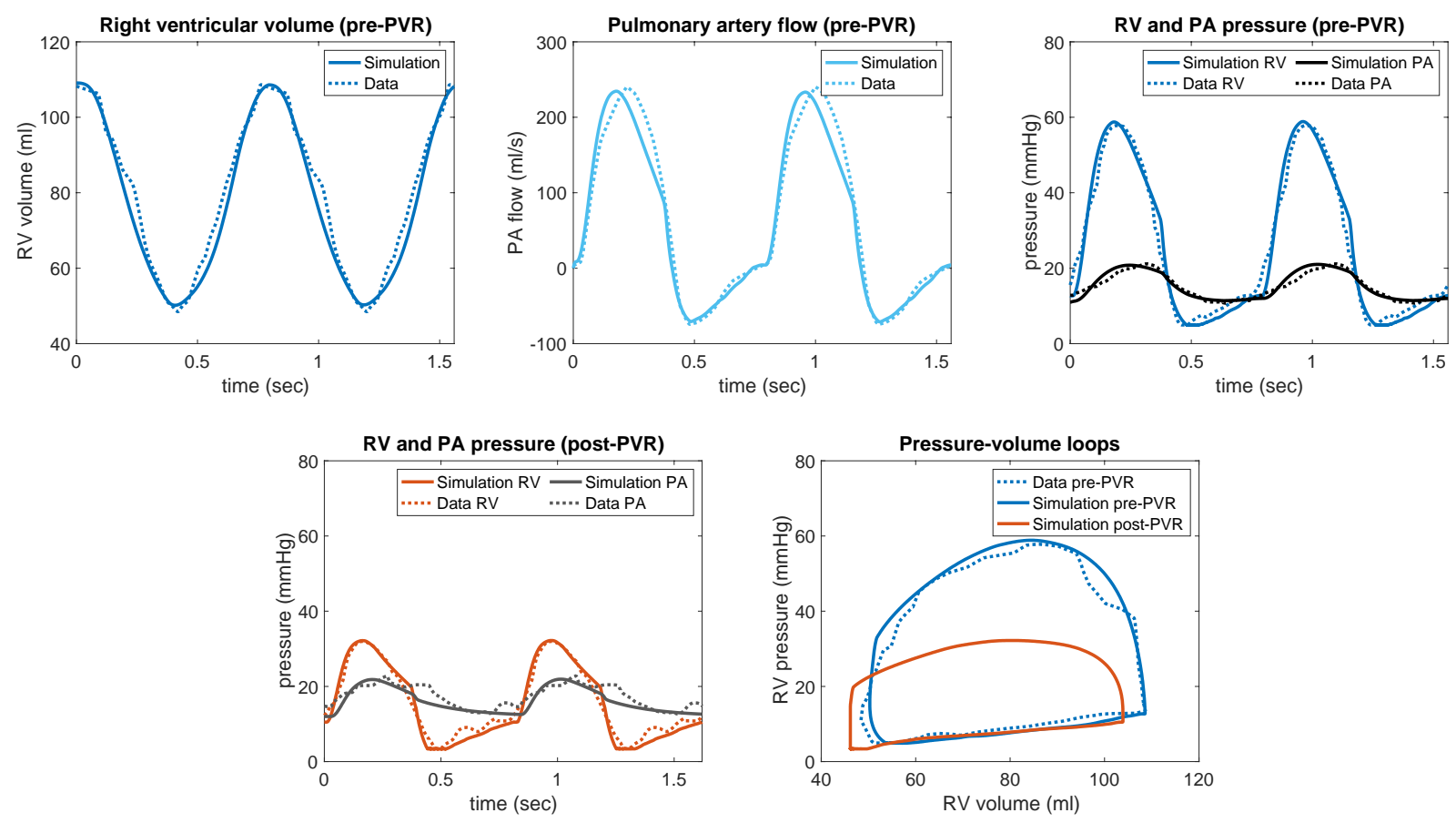

Figure 3: Measured data (dashed line) and simulation (solid line) for Patient \#16. 

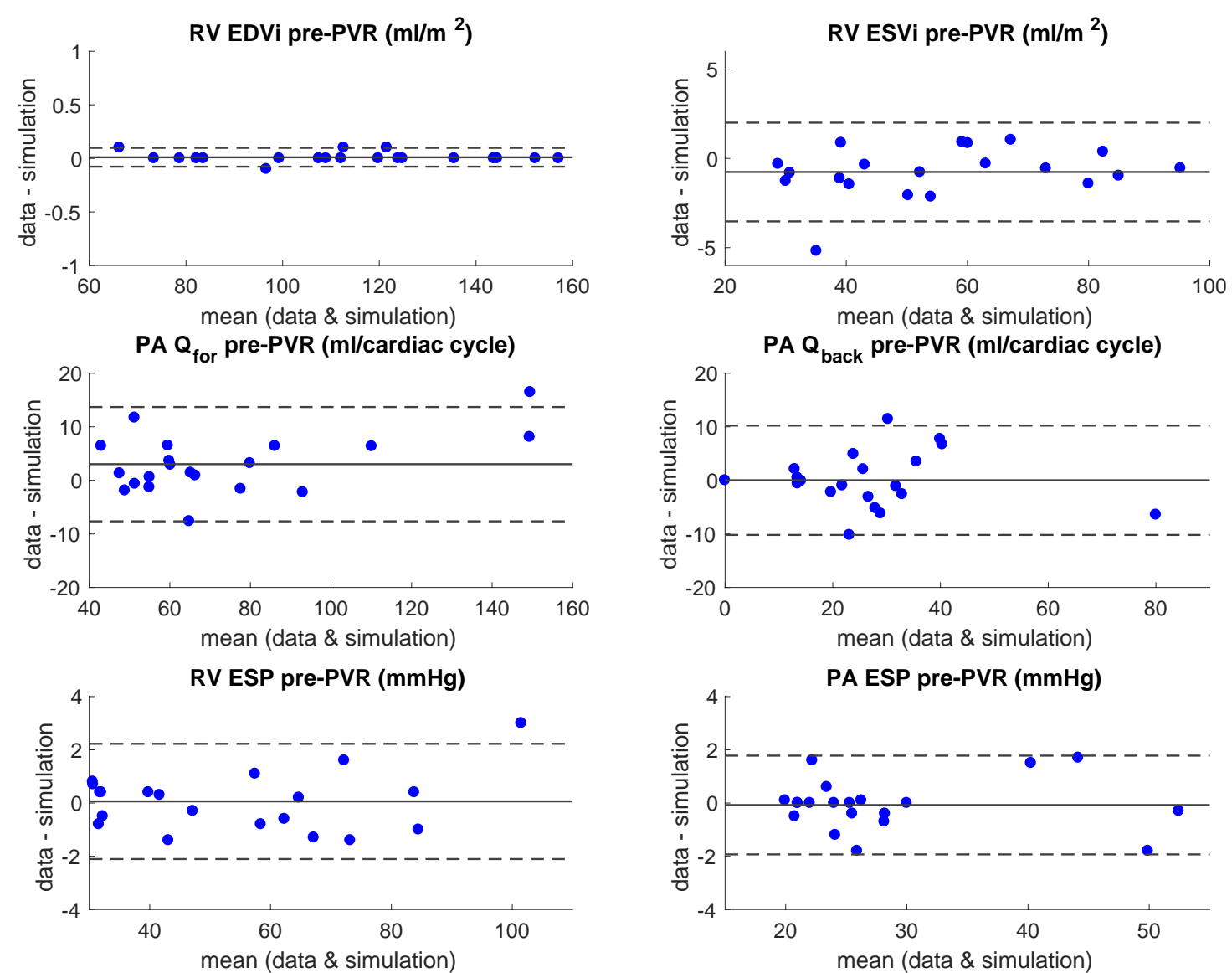

PA ESP pre-PVR (mmHg)
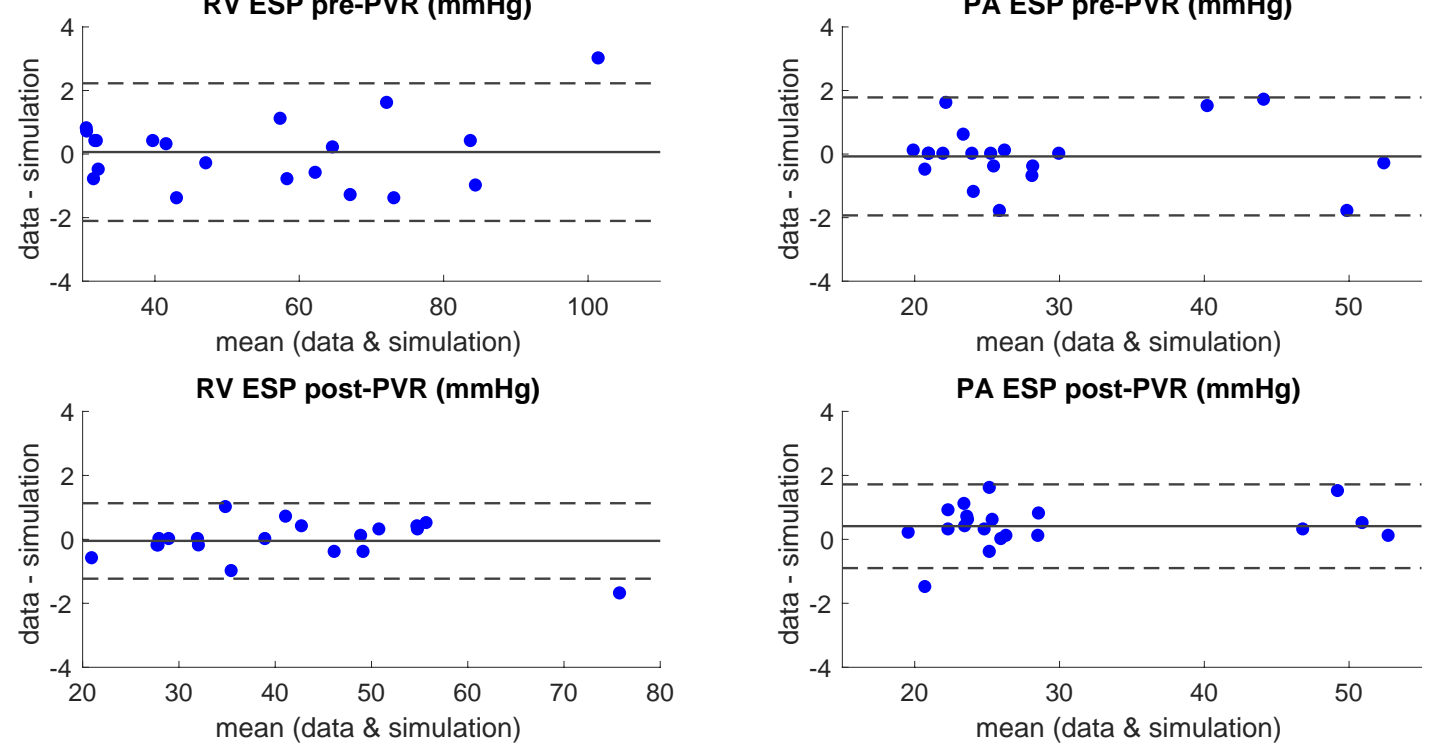

Figure 4: Bland-Altman plots for RV EDVi, ESVi, PA Qtor, Qback, RV ESP, PA ESP (all pre-PVR), and for RV ESP and PA ESP (post-PVR). Solid horizontal line represents the mean of the difference between data and simulation, top and bottom dashed horizontal lines show the limits of agreement at $95 \%$ prediction interval $( \pm 1.96$ times standard deviation). RV EDVi and ESVi: right ventricular end-diastolic and end-systolic volumes indexed to body surface area; PA Qfor and Qback: pulmonary artery forward and backward flow; RV ESP: right ventricular end-systolic pressure; PA ESP: pulmonary artery end-systolic pressure. 

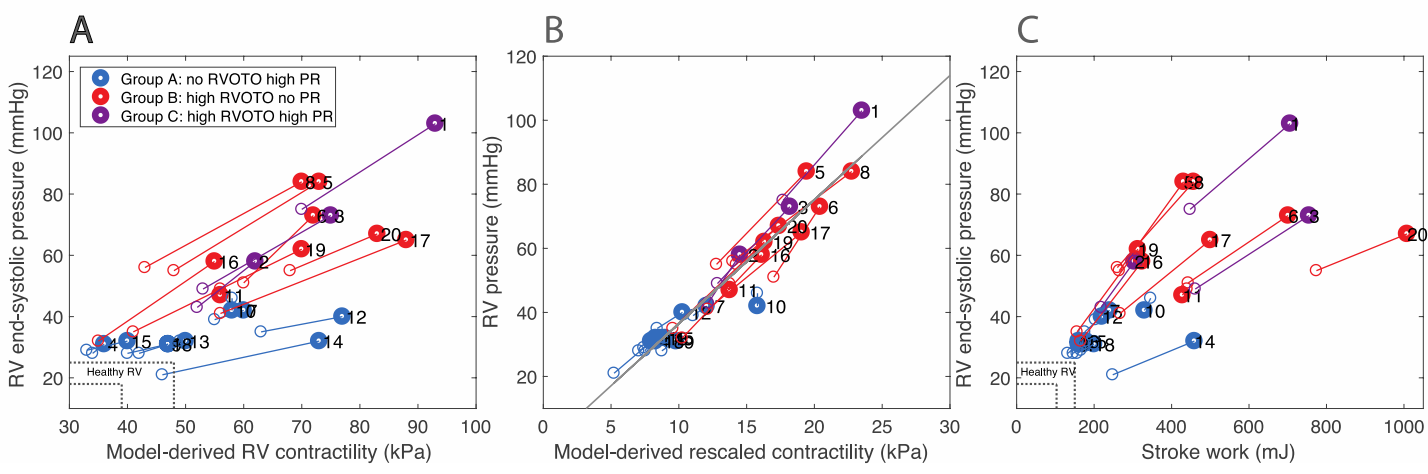

Figure 5: Model-derived RV contractility (A) and stroke work (C) for each patient. Filled and empty circles correspond to pre- and post-PVR values, respectively. The number labels of the circles correspond to individual patients. The values for healthy $\mathrm{RVs}$ are represented by the area encompassed within the dashed lines. B: RV contractility rescaled by the ratio of myocardial wall thickness over ventricular chamber radius against $\mathrm{RV}$ end-systolic pressure, where gray line is Pearson's correlation with $\mathrm{R}^{2}=0.95, \mathrm{p}<0.05$. 

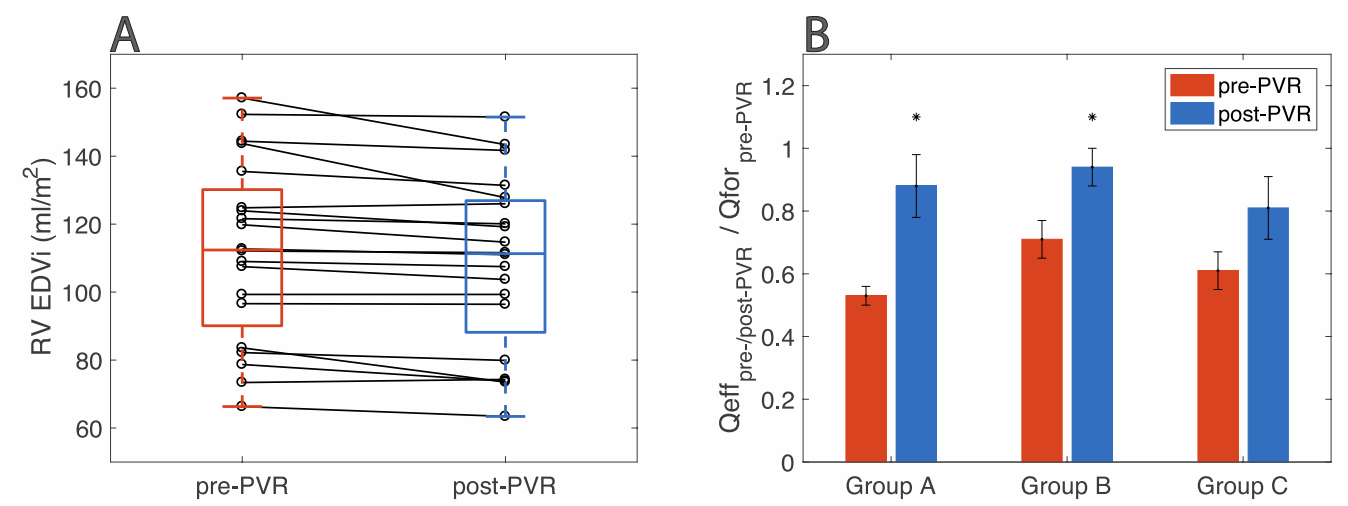

Figure 6 A: Model-predicted post-PVR changes in RV end-diastolic volumes indexed to body surface area (EDVi). Central line inside each box indicates the median, and the bottom and top edges of the boxes show $25^{\text {th }}$ and $75^{\text {th }}$ percentiles, respectively. Black circles connected by black lines show the EDVi change pre- and post-PVR for individual patients. B: Post-PVR model-predicted change in effective flow (Qeff) in each patient group. Orange bars: Qeff pre-PVR/Qforpre-PVR corresponding to the complement of regurgitation fraction (1- Qback/Qfor), where Qfor and Qback are forward and backward flows, respectively. Blue bars: Qeff post-PVR (model) is scaled by Qfor pre-PVR (data) (consistently with the orange bars) to demonstrate model predicted significant increase of Qeff post-PVR. Note, that model-derived Qeff / Qfor $=1$ for postPVR (due to the assumption of zero pulmonary regurgitation post-PVR). The stars indicate significant difference at $\mathrm{p}<0.05$. 


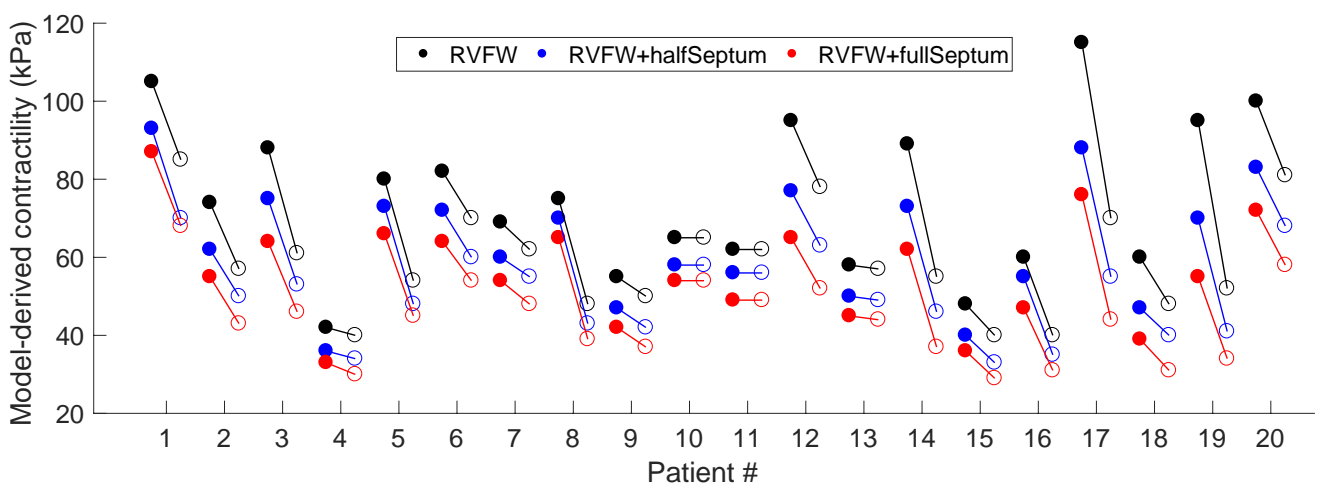

Figure 7: Sensitivity of the model-derived contractility to the variation of RV mass. Preand post-PVR contractilities (filled and empty points, respectively) were calibrated for the following type of mass input for each patient: $R V$ mass represented by $R V$ free wall (RVFW, black points); RVFW mass increased by the mass of half septum mass (blue points); and RVFW with full septum (red points). Solid lines between the points show the decrease of the model-derived contractility post-PVR. 


\section{Electronic Supplementary Material (figures)}
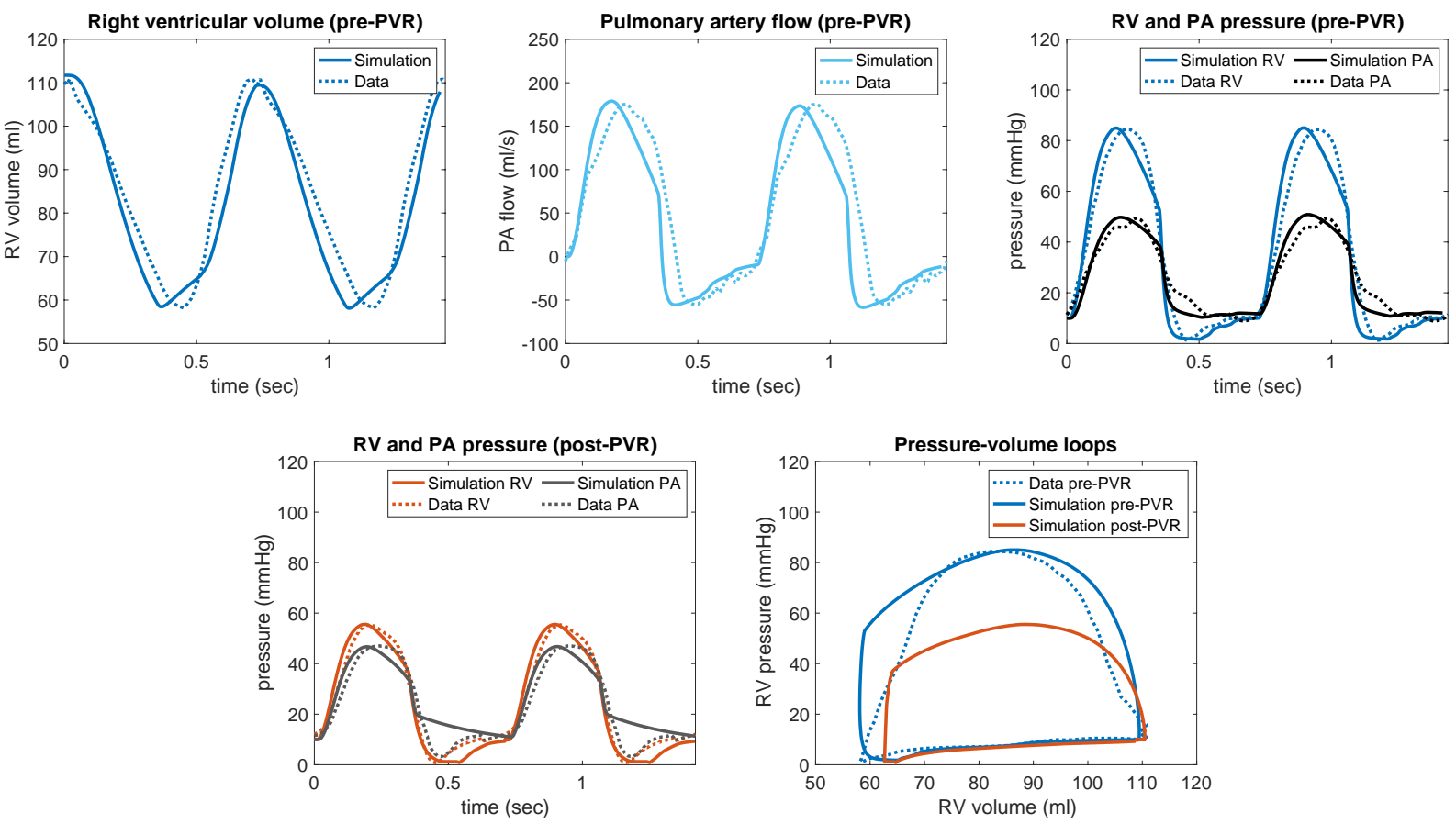

Supplementary Figure S1: Measured data (dashed line) and simulation (solid line) for Patient \#3. 

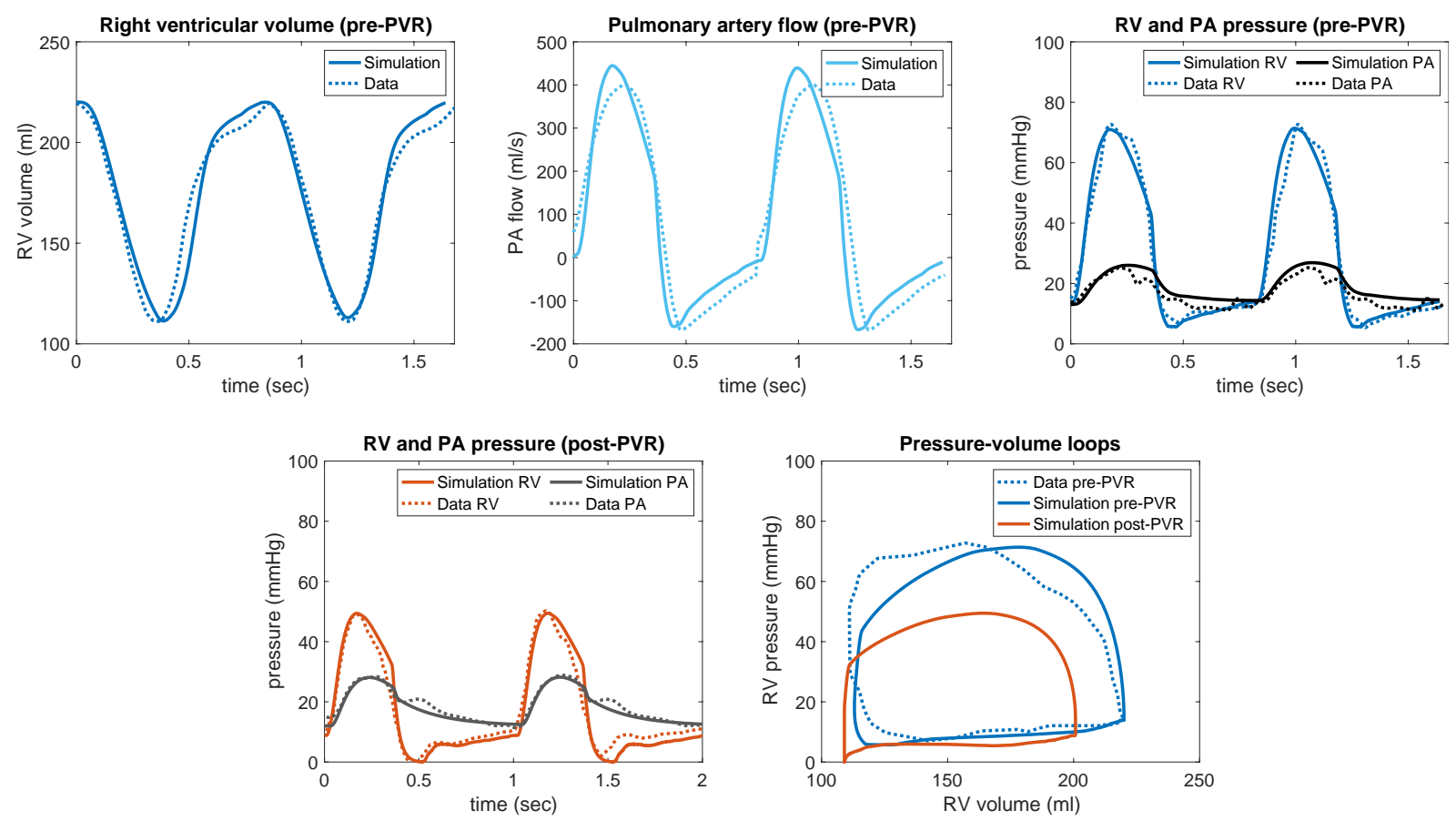

Supplementary Figure S2: Measured data (dashed line) and simulation (solid line) for Patient \#8. 

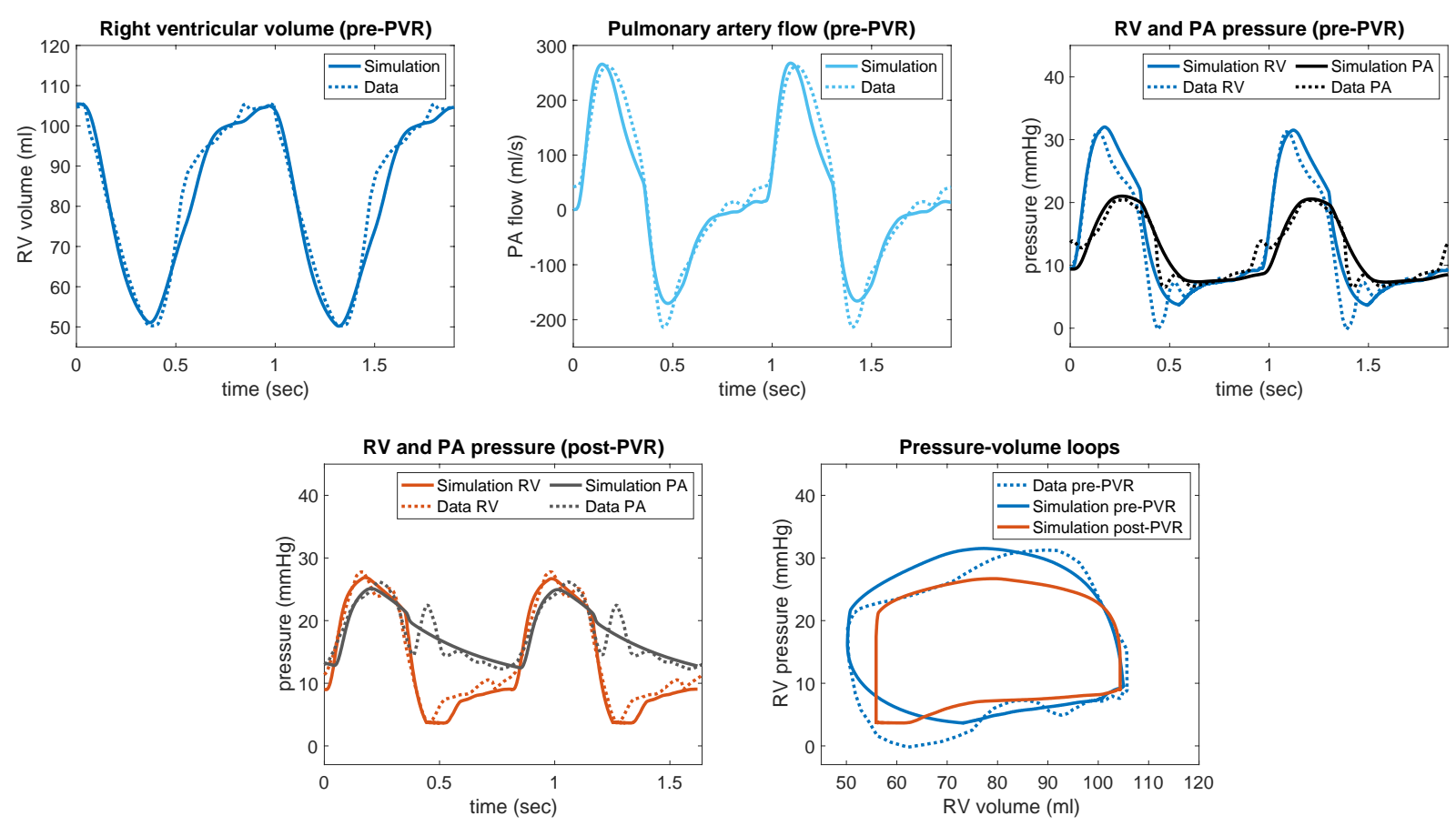

Supplementary Figure S3: Measured data (dashed line) and simulation (solid line) for Patient \#9. 


\section{References}

1. Vliegen Hubert W., van Straten Alexander, de Roos Albert, et al. Magnetic Resonance Imaging to Assess the Hemodynamic Effects of Pulmonary Valve Replacement in Adults Late After Repair of Tetralogy of Fallot. Circulation. 2002;106(13):1703-1707. doi:10.1161/01.CIR.0000030995.59403.F8

2. Quail MA, Frigiola A, Giardini A, et al. Impact of Pulmonary Valve Replacement in Tetralogy of Fallot With Pulmonary Regurgitation: A Comparison of Intervention and Nonintervention. Ann Thorac Surg. 2012;94(5):1619-1626.

doi:10.1016/j.athoracsur.2012.06.062

3. Bokma JP, Winter MM, Oosterhof T, et al. Preoperative thresholds for mid-to-late haemodynamic and clinical outcomes after pulmonary valve replacement in tetralogy of Fallot. Eur Heart J. 2016;37(10):829-835. doi:10.1093/eurheartj/ehv550

4. Dave HH, Buechel ERV, Dodge-Khatami A, et al. Early Insertion of a Pulmonary Valve for Chronic Regurgitation Helps Restoration of Ventricular Dimensions. Ann Thorac Surg. 2005;80(5):1615-1621. doi:10.1016/j.athoracsur.2005.04.058

5. Frigiola Alessandra, Hughes Marina, Turner Mark, et al. Physiological and Phenotypic Characteristics of Late Survivors of Tetralogy of Fallot Repair Who Are Free From Pulmonary Valve Replacement. Circulation. 2013;128(17):1861-1868. doi:10.1161/CIRCULATIONAHA.113.001600

6. Tweddell JS, Simpson P, Li S-H, et al. Timing and Technique of Pulmonary Valve Replacement in the Patient With Tetralogy of Fallot. Semin Thorac Cardiovasc Surg Pediatr Card Surg Annu. 2012;15(1):27-33. doi:10.1053/j.pcsu.2012.01.007

7. Therrien J, Provost Y, Merchant N, Williams W, Colman J, Webb G. Optimal timing for pulmonary valve replacement in adults after tetralogy of Fallot repair. Am J Cardiol. 2005;95(6):779-782. doi:10.1016/j.amjcard.2004.11.037

8. Geva T. Repaired tetralogy of Fallot: the roles of cardiovascular magnetic resonance in evaluating pathophysiology and for pulmonary valve replacement decision support. $J$ Cardiovasc Magn Reson. 2011;13(1):9. doi:10.1186/1532-429X-13-9

9. Valente AM, Gauvreau K, Assenza GE, et al. Contemporary predictors of death and sustained ventricular tachycardia in patients with repaired tetralogy of Fallot enrolled in the INDICATOR cohort. Heart. 2014;100(3):247-253. doi:10.1136/heartjnl-2013-304958

10. Wang VY, Nielsen PM, Nash MP. Image-Based Predictive Modeling of Heart Mechanics. Annu Rev Biomed Eng. 2015;17(1):351-383. doi:10.1146/annurev-bioeng-071114040609 
11. Chabiniok R, Wang VY, Hadjicharalambous M, et al. Multiphysics and multiscale modelling, data-model fusion and integration of organ physiology in the clinic: ventricular cardiac mechanics. Interface Focus. 2016;6(2). doi:10.1098/rsfs.2015.0083

12. Asner L, Hadjicharalambous $M$, Chabiniok R, et al. Estimation of passive and active properties in the human heart using 3D tagged MRI. Biomech Model Mechanobiol. 2016;15(5):1121-1139. doi:10.1007/s10237-015-0748-z

13. Chabiniok R, Moireau P, Lesault P-F, Rahmouni A, Deux J-F, Chapelle D. Estimation of tissue contractility from cardiac cine-MRI using a biomechanical heart model. Biomech Model Mechanobiol. 2012;11(5):609-630. doi:10.1007/s10237-011-0337-8

14. Ruijsink B, Zugaj K, Wong J, et al. Dobutamine stress testing in patients with Fontan circulation augmented by biomechanical modeling. PLOS ONE. 2020;15(2):e0229015. doi:10.1371/journal.pone.0229015

15. Genet M, Stoeck CT, von Deuster C, Lee LC, Kozerke S. Equilibrated warping: Finite element image registration with finite strain equilibrium gap regularization. Med Image Anal. 2018;50:1-22. doi:10.1016/j.media.2018.07.007

16. Castellanos DA, Skardova K, Bhattaru A, et al. Left ventricular torsion obtained using equilibrated warping in patients with repaired Tetralogy of Fallot. Pediatr Cardiol. Published online 2021.

17. Kawel-Boehm N, Maceira A, Valsangiacomo-Buechel ER, et al. Normal values for cardiovascular magnetic resonance in adults and children. $J$ Cardiovasc Magn Reson. 2015;17(1):29. doi:10.1186/s12968-015-0111-7

18. Caruel M, Chabiniok R, Moireau P, Lecarpentier Y, Chapelle D. Dimensional reductions of a cardiac model for effective validation and calibration. Biomech Model Mechanobiol. 2014;13(4):897-914. doi:10.1007/s10237-013-0544-6

19. Le Gall A, Vallée F, Pushparajah K, et al. Monitoring of cardiovascular physiology augmented by a patient-specific biomechanical model during general anesthesia. $A$ proof of concept study. PLOS ONE. 2020;15(5):e0232830.

doi:10.1371/journal.pone.0232830

20. Chapelle D, Tallec PL, Moireau P, Sorine M. An energy-preserving muscle tissue model: formulation and compatible discretizations. Int J Multiscale Comput Eng. 2012;10(2):189. doi:10.1615/IntJMultCompEng.2011002360

21. Huxley AF. Muscle structure and theories of contraction. Prog Biophys Biophys Chem. 1957;7:255-318.

22. Kimmig F, Chapelle D, Moireau P. Thermodynamic properties of muscle contraction models and associated discrete-time principles. Adv Model Simul Eng Sci. 2019;6(1):6. doi:10.1186/s40323-019-0128-9 
23. Stergiopulos N, Westerhof BE, Westerhof N. Total arterial inertance as the fourth element of the windkessel model. Am J Physiol. 1999;276(1):H81-88.

doi:10.1152/ajpheart.1999.276.1.H81

24. Sainte-Marie J, Chapelle D, Cimrman R, Sorine M. Modeling and estimation of the cardiac electromechanical activity. Comput Struct. 2006;84(28):1743-1759.

doi:10.1016/j.compstruc.2006.05.003

25. Klotz S, Hay I, Dickstein ML, et al. Single-beat estimation of end-diastolic pressurevolume relationship: a novel method with potential for noninvasive application. Am J Physiol-Heart Circ Physiol. 2006;291(1):H403-H412. doi:10.1152/ajpheart.01240.2005

26. Chabiniok R, Moireau P, Kiesewetter C, Hussain MT, Razavi R, Chapelle D. Assessment of atrioventricular valve regurgitation using biomechanical cardiac modeling. Funct Imaging Model Heart - 9th Int Conf FIMH 2017 Proc LCNS. Published online May 23, 2017:401411. doi:10.1007/978-3-319-59448-4_38

27. Lurz Philipp, Nordmeyer Johannes, Muthurangu Vivek, et al. Comparison of Bare Metal Stenting and Percutaneous Pulmonary Valve Implantation for Treatment of Right Ventricular Outflow Tract Obstruction. Circulation. 2009;119(23):2995-3001. doi:10.1161/CIRCULATIONAHA.108.836312

28. Švihlová H, Hron J, Málek J, Rajagopal KR, Rajagopal K. Determination of pressure data from velocity data with a view toward its application in cardiovascular mechanics. Part 1. Theoretical considerations. Int J Eng Sci. 2016;105:108-127. doi:10.1016/j.ijengsci.2015.11.002

29. Nagueh SF, Smiseth OA, Appleton CP, et al. Recommendations for the Evaluation of Left Ventricular Diastolic Function by Echocardiography: An Update from the American Society of Echocardiography and the European Association of Cardiovascular Imaging. J Am Soc Echocardiogr Off Publ Am Soc Echocardiogr. 2016;29(4):277-314. doi:10.1016/j.echo.2016.01.011

30. Janoušek Jan, Kovanda Jan, Ložek Miroslav, et al. Pulmonary Right Ventricular Resynchronization in Congenital Heart Disease. Circ Cardiovasc Imaging. 2017;10(9):e006424. doi:10.1161/CIRCIMAGING.117.006424

31. Wong J, Pushparajah K, de Vecchi A, et al. Pressure-volume loop-derived cardiac indices during dobutamine stress: a step towards understanding limitations in cardiac output in children with hypoplastic left heart syndrome. Int J Cardiol. 2017;230:439-446. doi:10.1016/j.ijcard.2016.12.087

32. Marx L, Gsell MAF, Rund A, et al. Personalization of electro-mechanical models of the pressure-overloaded left ventricle: fitting of Windkessel-type afterload models. Philos Trans R Soc Math Phys Eng Sci. 2020;378(2173):20190342. doi:10.1098/rsta.2019.0342

33. Genet M, Lee LC, Baillargeon B, Guccione JM, Kuhl E. Modeling Pathologies of Diastolic and Systolic Heart Failure. Ann Biomed Eng. 2016;44(1):112-127. doi:10.1007/s10439015-1351-2 
34. Göktepe S, Abilez OJ, Kuhl E. A generic approach towards finite growth with examples of athlete's heart, cardiac dilation, and cardiac wall thickening. J Mech Phys Solids.

2010;58(10):1661-1680. doi:10.1016/j.jmps.2010.07.003

35. Toussaint N, Stoeck CT, Schaeffter T, Kozerke S, Sermesant M, Batchelor PG. In vivo human cardiac fibre architecture estimation using shape-based diffusion tensor processing. Med Image Anal. 2013;17(8):1243-1255. doi:10.1016/j.media.2013.02.008

36. von Deuster C, Sammut E, Asner L, et al. Studying Dynamic Myofiber Aggregate Reorientation in Dilated Cardiomyopathy Using In Vivo Magnetic Resonance Diffusion Tensor Imaging. Circ Cardiovasc Imaging. 2016;9(10). doi:10.1161/CIRCIMAGING.116.005018

37. Lee LC, Genet M, Acevedo-Bolton G, Ordovas K, Guccione JM, Kuhl E. A computational model that predicts reverse growth in response to mechanical unloading. Biomech Model Mechanobiol. 2015;14(2):12. doi:10.1007/s10237-014-0598-0

38. Regazzoni F, Chapelle D, Moireau P. Combining Data Assimilation and Machine Learning to build data-driven models for unknown long time dynamics - Applications in cardiovascular modeling. Int J Numer Methods Biomed Eng. Published online 2021. doi:10.1002/cnm.3471 
Table 1. Demographics and patients' characteristics derived from measured data prior to and after pulmonary valve replacement (pre-PVR and post-PVR, respectively).

\begin{tabular}{|c|c|c|c|c|c|c|c|c|c|c|c|c|c|c|c|c|c|c|c|c|}
\hline & & & & \multicolumn{12}{|c|}{ pre-PVR } & \multicolumn{4}{|c|}{ post-PVR } & \multirow[b]{2}{*}{$\begin{array}{c}\text { Group } \\
(\#)\end{array}$} \\
\hline $\begin{array}{c}\text { Patient } \\
(\#)\end{array}$ & $\begin{array}{c}\text { age } \\
\text { (year) }\end{array}$ & sex & $\begin{array}{l}\text { BSA } \\
\left(m^{2}\right)\end{array}$ & $\begin{array}{l}\text { QRSd } \\
\text { (s) }\end{array}$ & $\begin{array}{c}\mathrm{HR} \\
\text { (beats/min) }\end{array}$ & $\begin{array}{c}\text { RVFW } \\
\text { mass } \\
(\mathrm{g})\end{array}$ & $\begin{array}{c}\text { Septum } \\
\text { mass } \\
(\mathrm{g})\end{array}$ & $\begin{array}{l}\text { EDVi } \\
\left(\mathrm{ml} / \mathrm{m}^{2}\right)\end{array}$ & $\begin{array}{l}\mathrm{ESVi} \\
\left(\mathrm{ml} / \mathrm{m}^{2}\right)\end{array}$ & $\begin{array}{l}\text { EF } \\
(\%)\end{array}$ & $\begin{array}{l}\text { PR } \\
(\%)\end{array}$ & $\begin{array}{l}\text { TR } \\
(\%)\end{array}$ & $\begin{array}{l}\text { LV ESP } \\
(\mathrm{mmHg})\end{array}$ & $\begin{array}{l}\text { RV ESP } \\
\text { (mmHg) }\end{array}$ & $\begin{array}{l}\text { PA ESP } \\
(\mathrm{mmHg})\end{array}$ & $\begin{array}{l}\text { QRSd } \\
\text { (s) }\end{array}$ & $\begin{array}{c}\mathrm{HR} \\
\text { (beats/min) }\end{array}$ & $\begin{array}{c}\text { RV } \\
\text { ESP } \\
(\mathrm{mmHg})\end{array}$ & $\begin{array}{c}\mathrm{PA} \\
\mathrm{ESP} \\
(\mathrm{mmHg})\end{array}$ & \\
\hline 1 & 12 & $\mathrm{~F}$ & 1.21 & 0.165 & 61 & 70 & 26 & 136 & 83 & 39 & 47 & - & - & 103 & 45 & 0.147 & 58 & 75 & 50 & C \\
\hline 2 & 8 & $\mathrm{M}$ & 0.86 & 0.137 & 63 & 40 & 16 & 120 & 60 & 50 & 36 & - & 85 & 58 & 28 & 0.098 & 67 & 43 & 26 & C \\
\hline 3 & 13 & $\mathrm{M}$ & 1.40 & 0.166 & 72 & 85 & 41 & 157 & 79 & 50 & 39 & - & 90 & 73 & 25 & 0.147 & 59 & 49 & 29 & C \\
\hline 4 & 11 & $F$ & 0.97 & 0.158 & 64 & 44 & 18 & 122 & 63 & 48 & 58 & - & 77 & 31 & 23 & 0.120 & 79 & 28 & 24 & A \\
\hline 5 & 9 & $\mathrm{~F}$ & 0.99 & 0.137 & 85 & 70 & 20 & 144 & 95 & 34 & 29 & - & 91 & 84 & 49 & 0.098 & 86 & 55 & 51 & B \\
\hline 6 & 11 & $\mathrm{~F}$ & 1.34 & 0.086 & 70 & 70 & 25 & 107 & 40 & 63 & 29 & - & 101 & 73 & 28 & 0.090 & 71 & 51 & 24 & B \\
\hline 7 & 8 & $\mathrm{M}$ & 0.87 & 0.126 & 81 & 33 & 12 & 113 & 40 & 65 & 46 & 10 & 69 & 42 & 24 & 0.126 & 68 & 39 & 25 & A \\
\hline 8 & 8 & $\mathrm{~F}$ & 0.99 & 0.159 & 85 & 70 & 18 & 112 & 60 & 47 & 30 & 11 & 89 & 84 & 49 & 0.156 & 84 & 56 & 47 & B \\
\hline 9 & 11 & $F$ & 0.97 & 0.160 & 64 & 35 & 18 & 109 & 52 & 53 & 59 & - & 76 & 31 & 20 & 0.145 & 75 & 28 & 26 & $\bar{A}$ \\
\hline 10 & 11 & $\mathrm{~F}$ & 1.34 & 0.089 & 74 & 66 & 19 & 99 & 32 & 68 & 29 & - & 105 & 42 & 24 & 0.093 & 67 & 46 & 26 & A \\
\hline 11 & 17 & $M$ & 2.23 & 0.165 & 61 & 69 & 28 & 73 & 29 & 61 & 0 & 18 & 87 & 47 & 21 & 0.151 & 61 & 49 & 24 & B \\
\hline 12 & 6 & $M$ & 0.84 & 0.129 & 87 & 25 & 15 & 152 & 85 & 44 & 47 & - & 99 & 40 & 26 & 0.129 & 91 & 35 & 26 & A \\
\hline 13 & 8 & $M$ & 1.18 & 0.117 & 87 & 31 & 13 & 97 & 49 & 49 & 46 & - & - & 32 & 25 & 0.115 & 86 & 32 & 25 & A \\
\hline 14 & 16 & $F$ & 2.02 & 0.133 & 59 & 47 & 26 & 144 & 73 & 49 & 49 & - & 96 & 32 & 25 & 0.104 & 58 & 21 & 21 & A \\
\hline 15 & 26 & $F$ & 1.69 & 0.147 & 67 & 47 & 19 & 79 & 38 & 51 & 35 & 10 & 93 & 32 & 24 & 0.133 & 68 & 29 & 24 & $\mathbf{A}$ \\
\hline 16 & 17 & $\mathrm{~F}$ & 1.64 & 0.163 & 75 & 55 & 23 & 66 & 29 & 56 & 21 & - & 88 & 58 & 21 & 0.164 & 74 & 32 & 23 & B \\
\hline 17 & 15 & $M$ & 1.52 & 0.129 & 74 & 40 & 28 & 84 & 30 & 64 & 24 & - & 76 & 65 & 22 & 0.110 & 79 & 41 & 22 & B \\
\hline 18 & 11 & $F$ & 1.17 & 0.096 & 95 & 37 & 27 & 124 & 68 & 45 & 47 & - & 78 & 31 & 20 & 0.101 & 88 & 28 & 20 & A \\
\hline 19 & 13 & $\mathrm{~F}$ & 1.29 & 0.146 & 79 & 33 & 29 & 82 & 43 & 48 & 29 & - & 86 & 62 & 30 & 0.135 & 76 & 35 & 29 & B \\
\hline 20 & 19 & $\mathrm{~F}$ & 2.10 & 0.129 & 75 & 84 & 42 & 125 & 53 & 58 & 29 & - & 85 & 67 & 41 & 0.120 & 50 & 55 & 53 & B \\
\hline Healthy & 12 & & 1.2 & 0.11 & 73 & 25 & 14 & 100 & 47 & 54 & - & - & 100 & 18-25 & $18-25$ & - & - & - & - & - \\
\hline
\end{tabular}

HR: heart rate; LV, RV and PA ESP: LV, RV and pulmonary artery end-systolic pressures; PR: pulmonary valve regurgitation fraction; QRSd: duration of QRS complex measured in ECG; RVFW mass: right ventricular free wall mass; RV EDVi and ESVi: RV end-diastolic and end-systolic volumes indexed to body surface area (BSA); RV EF: RV ejection fraction; TR: tricuspid valve regurgitation fraction. 
Table 2. Bland-Altman quantitative statistics summarizing the mean bias \pm standard deviation (SD) and limits of agreement (95\%-confidence interval) between simulations and measurements.

\begin{tabular}{|c|c|c|}
\hline & mean \pm SD & 95\%-confidence interval \\
\hline \multicolumn{3}{|l|}{ Pre-PVR } \\
\hline RV EDVi $\left(\mathrm{ml} / \mathrm{m}^{2}\right)$ & $0.01 \pm 0.04$ & -0.08 to 0.01 \\
\hline RV ESVi $\left(\mathrm{ml} / \mathrm{m}^{2}\right)$ & $-0.77 \pm 1.41$ & -3.53 to 2.00 \\
\hline RV ESP $(\mathrm{mmHg})$ & $0.06 \pm 1.10$ & -2.11 to 2.23 \\
\hline PA ESP $(\mathrm{mmHg})$ & $-0.08 \pm 0.95$ & -1.93 to 1.78 \\
\hline PA Qfor (ml/cardiac cycle) & $3.0 \pm 5.4$ & -7.6 to 13.7 \\
\hline PA Qback (ml/cardiac cycle) & $0.01 \pm 5.00$ & 10.20 to 10.20 \\
\hline \multicolumn{3}{|l|}{ Post-PVR } \\
\hline $\mathrm{RV} \operatorname{ESP}(\mathrm{mmHg})$ & $-0.05 \pm 0.60$ & 1.23 to 1.13 \\
\hline PA ESP & $0.41 \pm 0.67$ & -0.90 to 1.72 \\
\hline
\end{tabular}

EDVi, end-diastolic volume indexed to body surface area; ESP, end-systolic pressure; ESVi, end-systolic volume indexed to body surface area; PA, pulmonary artery; PVR: pulmonary valve replacement; Qfor, forward flow; RV, right ventricle. 
Table 3. Median right ventricular (RV) contractility and relative contractility with respect to the normal RV contractility (48 kPa); and median RV stroke work and relative stroke work with respect to normal RV stroke work (150 mJ). Group A: no RVOTO and high PR; Group B: high RVOTO and no PR; Group C: high RVOTO and high PR. Significance is assumed at $p<0.05$.

\begin{tabular}{|c|c|c|c|c|c|c|c|c|}
\hline & \multicolumn{2}{|c|}{$\begin{array}{c}\text { Contractility } \\
(\mathrm{kPa})\end{array}$} & \multicolumn{2}{|c|}{$\begin{array}{l}\text { Contractility with } \\
\text { respect to normal }\end{array}$} & \multicolumn{2}{|c|}{$\begin{array}{c}\text { Stroke work } \\
(\mathrm{mJ})\end{array}$} & \multicolumn{2}{|c|}{$\begin{array}{l}\text { Stroke work with } \\
\text { respect to normal }\end{array}$} \\
\hline & Pre-PVR & Post-PVR & Pre-PVR & Post-PVR & Pre-PVR & Post-PVR & Pre-PVR & Post-PVR \\
\hline Group A & 50 & $46(p=0.008)$ & $+4 \%$ & $0 \%$ & 200 & $166(p=0.027)$ & $+34 \%$ & $+10 \%$ \\
\hline Group B & 71 & $52(p=0.016)$ & $+48 \%$ & $+8 \%$ & 444 & $266(p=0.016)$ & $+196 \%$ & $+77 \%$ \\
\hline Group C & 75 & $53(p=0.250)$ & $+56 \%$ & $+10 \%$ & 706 & $448(p=0.250)$ & $+370 \%$ & $+199 \%$ \\
\hline All patients & 66 & $51(p=0.000)$ & $+38 \%$ & $+5 \%$ & 327 & $233(p=0.000)$ & $+118 \%$ & $+55 \%$ \\
\hline
\end{tabular}

PR: pulmonary regurgitation; RVOTO: right ventricular outflow tract obstruction. 